\title{
Can you model growth of trust? A study of the sustainability of a rural community health centre in north India
}

\begin{abstract}
Trust in the service provided by any health facility is of vital importance to its sustainability, whether it is a community clinic in a rural area of a developing country or an international telemedicine service. Community health centres can be used as a means of delivering highly accessible, low-cost health service in the developing world. A major strategic issue for planners of such centres is the expected level of uptake of services throughout a region and its effect on sustainability of any facility. In this study of a clinic in rural north India, Monte Carlo simulation is used in modelling the spatiotemporal spread of usage of the service. Trust in the provider is built both through word-of-mouth contacts and previous development activities: our study contributes to the literature with a practical application of trust modelling.

keywords(trust; sustainability; Monte Carlo simulation; OR for developing countries; OR for health service; word-of-mouth spread)
\end{abstract}

\section{Introduction}

Trust in the service provided by any health facility is of vital importance to its sustainability: this is particularly the case for community clinics in rural areas of a developing countries. Such health centres can be of great importance in providing much needed basic healthcare services such as ante-natal checks, child vaccination and treatment for minor illnesses. However, it is only with trust in a provider that the local population will consider using new services. In developing countries, it is common practice to seek help from untrained practitioners and barriers to changing long-established habits must be overcome before a new service can become sustainable.

The importance of trust in a healthcare provider and its link with utilisation of services on offer is highlighted by several recent authors (Ozawa and Sripad, 2013; Brennan et al, 2013). In a study of urban dwellers in Sri Lanka, Russell (2005) investigates trust and access to treatment through both state and private health care by low income households. Rao et al (2013) also study trust in healthcare providers in a rural developing country context, with a study of trust in physicians and non-physician clinicians in Chhattisgarh, India.

Sustainability of any rural community centre is a high priority; loss of a facility is particularly serious to a poorly-resourced region. Here we take a broad view of sustainability, drawing links between its economic, societal and environmental components. A facility that is economically sustainable will provide a lasting resource to society. Societal factors, including build-up of trust, are of importance in the sustainability of a community facility (Smith et al, 2009). Moreover, in a region where subsistence or life preservation 
is the main aim, a healthcare centre provided in a community will enable those in the vicinity to use it without squandering precious environmental resources in travelling further afield.

The operation of a facility may be maintained through continuing funding, either self-funding or through an external agency: in either case, sufficient demand for the service is needed to maintain or justify its existence. In the not-for-profit sector, a self-sustaining clinic is free from dependence on outside funding, which may be subject to changes of priorities.

The target level of usage and the time taken to reach that level is of critical importance in achieving sustainability, as funding may be available for a limited time period only. We suggest that it is by build-up of trust that usage of a centre reaches the critical level for sustainability. We model the spatio-temporal spread of usage of such facilities: our novel inclusion of a trust factor gives a methodology that is applicable in rural areas where trust in a provider is gained by word-of-mouth contacts.

As a case study, we model the build-up of trust and usage of a mother-and-child clinic in the village of Paltandih, near Utraula, in a rural area of Uttar Pradesh (UP), India. The clinic was set up in 2005 with the goal of it being self-sustainable within two years, after initial funding. This has been a region of particularly high maternal and infant mortality, with assistance at childbirth being mostly provided by untrained practitioners. Knowledge of the clinic and its reputation are spread by word of mouth from its immediate neighbourhood. Customers for this low-charging facility operated by a non-governmental organisation (NGO) gain trust in the services provided through the previous experience of others living nearby, and in neighbouring villages. Trust is also built through development work, such as literacy classes, carried out in the villages.

This study uses Monte Carlo simulation to model numbers of customers arriving at this clinic from villages in the surrounding area. In accordance with the data analysed, it is assumed that within a certain distance from a clinic all the local population will know about the clinic and have sufficient knowledge and trust in what is provided to use its services where appropriate. Further afield, it is assumed that take-up of services is influenced by word-of-mouth spread of positive experiences of using the clinic, but that such take-up is random and it may also cease randomly.

The paper proceeds as follows. Previous research is reviewed in Section 2. Section 3 provides a background to the case study. Data preparation and preliminary analysis of data from the Paltandih clinic are described in Section 4. Spatio-temporal modelling is proposed in Section 5 and parameters are estimated in Section 6. Section 7 gives results of simulation and Sections 8 and 9 add discussion and a conclusion.

\section{Literature}

Our novel subject matter brings together diverse areas of previous research. Firstly, we consider definitions of trust itself and follow on with modelling in fields related to trust, namely rumour and influence modelling and cyber-networks. We turn next to epidemiological models of geographical spread of disease, which have relevance to our topic, although our subject is the spread of trust in a geographically-fixed entity. Finally, we consider models of demand specifically for healthcare facilities.

With research having been carried out into the nature of trust in a wide range of different disciplines, from psychology to cyber-networks, it is not surprising that an over-arching definition of trust has failed 
to appear (Lewis and Weigert, 1985; Shapiro, 1987; Hosmer, 1995; McKnight and Chervany, 2001). However, despite the inherent difficulties, McKnight and Chervany (2001) succeed in presenting a series of trust constructs derived from diverse research that can assist measurement and modelling. Firstly, characteristics of the trustee (whether trusted person or institution) are categorised into the following four groups: "benevolence", "integrity", "competence" and "predictability". Secondly, conceptual trust types or states of trusting are grouped: "disposition to trust", "institution-based trust", "trusting beliefs", "trusting intentions" and "trust-related behaviour". Interrelationships between these trust types and trustee characteristics are mapped, and we highlight here the relevance to trust in a community health centre. For example, individuals can move from a trusting disposition, or general willingness to trust, to particular trust in a health-care provider or to trusting belief about a health worker, given belief in the characteristics of the trustee. From these states, individuals can move to intentions to trust should the need arise for treatment, and thence to presenting for treatment, again assuming dependence on the characteristics of the trustee. However, Lewis and Weigert (1985) posit that, from a sociological standpoint, trust must be seen as a group property rather than as an individual's belief. Indeed, according to Gladwell (2000), the build-up of trust in a provider could be said to have reached a tipping point within a group or network when it is generally thought to be appropriate to use the facility when need arises.

Some mathematical interest has been attracted to rumour modelling, which is relevant in our context of the spreading of information. Classical rumour modelling originates with Daley and Kendall (1965), with a stochastic model of rumours as opposed to epidemics. Maki and Thompson (1973) provide a discretetime Markov model of rumour spreading through a simplified network of telephone links between isolated villages. Each village's interest in rumour spreading lasts only under defined conditions: the lifetime of a rumour is calculated under these assumptions. Belen et al (2011) describe the sociological meaning of rumour, and propose a continuous time model for dynamical spread of a rumour in a homogeneous population to find long-term proportions of "spreaders", "ignorants" and "stiflers". "Spreaders" pass on a rumour; "ignorants" do not know the rumour and "stiflers" have heard the rumour but either forget it or choose not to pass it on.

A number of linear models have been developed to represent the way that opinions are influenced by those of other people (French, 1956; DeGroot, 1974; Marsden and Friedkin, 1994), with new attitudes formed by weighting previous attitudes. Friedkin (1986) introduces a probabilistic element to modelling of influences. Links are activated with a certain probability, enabling alternative possible outcomes of consensus and disagreement to occur. Further generalisations are made (Friedkin and Johnsen, 1990) by introducing covariates that determine initial attitudes and continue to have an effect on subsequent attitudes. Markov-like modelling is used, but with a perhaps unrealistic discrete-time assumption. The effects of geographical adjacency in influence has been investigated in levels of resistance in nineteenthcentury Paris (Gould, 1991), in insurgency in the Philippines and in voting patterns in Louisiana (Doreian, 1981). Land et al (1991) report spatial effects on church attendance in U.S. counties.

Interest in modelling trust in cyber-networks has emerged in recent years, generally taking the form of agent-based modelling of trust between organisations or in systems. A review of agent-based trust modelling in large, open, distributed systems is given by Ramchurn et al (2004). Marsh and Dibben (2005) discuss levels of trust, differentiating between "untrust", being a lack of trust leading to absence of committing action, and distrust, where potentially harming attitudes are assumed in other parties. 
In the healthcare sphere, trust/distrust relationships between an acute stroke ward and a rehabilitation ward are modelled by Kethers et al (2005), using strategic dependency (Yu, 1995) and strategic rationale modelling (Gans et al, 2003).

Epidemiological studies of spread of disease form a complex and well-researched field, which we cannot aim to cover here but just provide pertinent examples. Classically, differential equations are used to describe the relationships between susceptible and infected members of the population. The homogenous mixing assumption is made, in other words that all susceptible members of a population are equally likely to become infected. For example, this assumption underlies the model of Roberts et al (2007) for spread of pandemic influenza in cities of New Zealand. However this assumption is not appropriate in situations where proximity to a source of infection brings increased probability of becoming infected. Geographical spread of disease thus requires different assumptions.

The spread between farms of diseases affecting cattle has provided examples of geographical disease modelling. Boender et al (2007) develop an epidemiologically-based model for the spread of diseases such as foot-and-mouth disease and avian influenza. The probability of disease at one farm infecting a neighbouring farm is assumed to be a function only of the distance apart of the farms. The density of farms in an area is thus a key factor in determining the spread of disease. This modelling was carried out with the purpose of predicting areas at risk of a major outbreak if infection is introduced. In such areas, infections would not die out naturally and interventions would be needed to eradicate the disease.

The diffusion of human disease in a geographical region is also a continuing subject for model creation. $\mathrm{Xu}$ et al (2006) assume that the probability of passing on disease between people is inversely proportional to Euclidean distance apart. In this study of disease spread in a metric network, the effect of distance is compared to the effect of hubs in the spread of disease. Contrastingly, multidimensional scaling (MDS) is the basis of modelling by Smallman-Raynor and Cliff (2004) of the spread of cholera in the first major wave of infection affecting the British Army in the Crimea, from 1854 to 1855. This technique enables contexts other than distance to describe 'closeness': in this example, connectivity between army camps defines closeness. Several regression models are used to predict the time at which cholera infection arrives at a camp, based on distance from infected camps in 'connectivity space'.

Several behavioural (i.e. non-mathematical) models have been formulated for predicting use of healthcare facilities (Andersen, 1995). A number of factors are highlighted as affecting the likelihood of use of health services:

- predisposing characteristics, e.g. age, gender, status, resources, healthy or unhealthy environment, beliefs about health and health services;

- enabling resources, both availability of facilities and personal resources, e.g. know-how, income, health insurance, time, travel, social relationships;

- need, whether perceived or diagnosed.

Use of a service affects subsequent likelihood of using the service and the perception of need to access that service. A survey of choices between types of therapy and providers in the Ivory Coast (Lasker, 1981) finds that choice is generally made on the grounds of accessibility in terms of cost of treatment and medicines, time spent in access and communication ease or problems. Previous experience of the 
provider, and opinions expressed in the sick person's social network are found to be of importance. In modelling access to hospital departments, Stummer et al (2004) recommend that factors to be taken into account should include hospital size, technological advancement and reputation, the referring practitioners' contacts and patients' socio-economic groups.

The prediction of demand for facilities has been made using several methodologies. Utility estimation has provided one such basis, as for example gravity or spatial interaction models (Huff, 1964) and competing destination models (Fotheringham, 1983). Several authors assume that customers will minimise the sum of costs incurred (Heinhold, 1978; Grossman and Brandeau, 2002), including travel costs and the costs of time spent queueing and being served. Flow demand modelling is proposed by Oliveira (2004) to predict hospital utilisation within Portugal. The effect of distance to services is said to vary with severity of illness, curative or preventative care, and hospital or primary care.

A number of distance-demand functions, describing the drop-off of demand for health facilities with distance, are suggested in the literature. These include exponential (Schultz, 1970; Hodgson, 1988), exponential with squared distance (Müller et al, 1998) and power functions (Fotheringham, 1983). It should be noted that Schultz (1970) assumes distance-demand functions that differ by level of the hierarchical service. Several authors (Brandeau et al, 1995; Marianov and Serra, 2001) model demand as Poisson, with rate varying exponentially with distance. Analysis of the usage of a small rural health centre in Papua New Guinea (Müller et al, 1998) shows only a small amount of drop-off in usage by distance close to the centre, but a steeper, or "bell-shaped" decline further away.

\section{Background to case study: the Paltandih Reproductive and Child Health Clinic}

The Paltandih Reproductive and Child Health (RCH) Clinic was set up in 2005 in Uttar Pradesh State, north India. The aim was for it to be self-sustaining within two years. This study was undertaken to investigate the conditions for sustainability from the point of view of build-up of usage of the clinic from the surrounding area.

The Paltandih RCH clinic was set up by Prem Sewa Hospital (PSH), in Gaindas Bujurg Block, Balrampur District. PSH, established in Utraula in 1966 (PSH, 2007) and now part of Emmanuel Hospital Association, has an excellent reputation for services to women and children. However, in the rural areas surrounding the hospital, most women have not had access to ante-natal care, and there has been an exceptionally high maternal and infant mortality in the district (PSH, 2007). Lack of knowledge and local custom can prevent women seeking help with childbirth. The Paltandih clinic was set up with the intention that this should be a sustainable development for the region. It was hoped that the income from small fees paid by clinic patients would eventually build up to a level that would sustain operations, once initial funding had ceased.

This is not considered to be a competitive situation for the Paltandih clinic, as the high quality medical service provided is of a different nature from that provided by any untrained medical practitioners, and government facilities are hard to access. This is a typical situation in remote rural areas of developing countries.

The conditions in the area surrounding the Paltandih clinic are typical for rural areas of developing 
countries. Travel in such a rural area is generally on foot and is not undertaken without good reason, particularly in a subsistence farming area. It is only a sufficiently serious perception of ill-health and trust or belief in the benefits of treatment that will cause use of such a clinic, given low, affordable costs. The disbenefits of travel to a clinic may also be compensated for by the benefit of using other services in the area, such as markets if present.

The barriers to usage of the clinic can be considered to be distance travelled on foot and adherence to customs in healthcare access. PSH carries out development work in the region such as literacy classes, adolescent groups and women's self-help groups. Such work is able to inform and change attitudes to seeking quality medical care.

\section{Data preparation and preliminary analysis}

Data on patient visits were made available from the Paltandih Clinic, and analysis was carried out of records covering a period of nineteen months from the clinic's inception in August 2005 until February 2007. This section describes data preparation and preliminary analysis.

\subsection{Data collection and preparation}

Hand-written records of clinic usage by individuals on a daily basis were transcribed into anonymised electronic form. Maps of the panchayats (groups of villages) in the area, together with 1991 and 2001 census data (Census of India, 1991, 2001) were used to find locations and populations of places from which usage of the clinic occurs. Figure 1 shows main usage of the clinic from villages in Gaindas Bujurg Block, along with the location of the clinic and PSH.

Difficulty was encountered, however, in deciphering the names of home villages of clients using the clinic, and with finding the locations and populations of these villages. Only key villages were marked on the maps available; sometimes the panchayat of a client was recorded, sometimes the village. The 2001 Census gave only panchayat populations; some individual village populations were available from the 1991 Census. At first only hand-drawn maps were available; some locations are now shown on Google Maps®. These difficulties can be considered typical of those encountered when researching in a developing country.

\subsection{Preliminary analysis of clinic usage}

This section describes patterns observed in the usage of the Paltandih clinic, with illustrations at village level and as demand spreads across the locality.

Early clinic users came from close-by villages. It is observed that people from these villages made use of the Paltandih clinic continuously over the period of observation, while usage from more distant villages was less consistent, as exemplified in Figure 2. However, very close villages, such as Paltandih itself (see Figure 2) did not take up usage initially, unlike slightly more distant villages. This initial reluctance may be for cultural reasons, such as desire for privacy or distrust of what is too familiar. However, over time, usage from neighbouring villages seems to influence potential clients in the very close vicinity of the clinic.

Figure 3 and Table 1 summarise the observed patterns of usage. We term 'consistent' the usage from villages that continues to the end of the observation period, once uptake has begun. We term as 


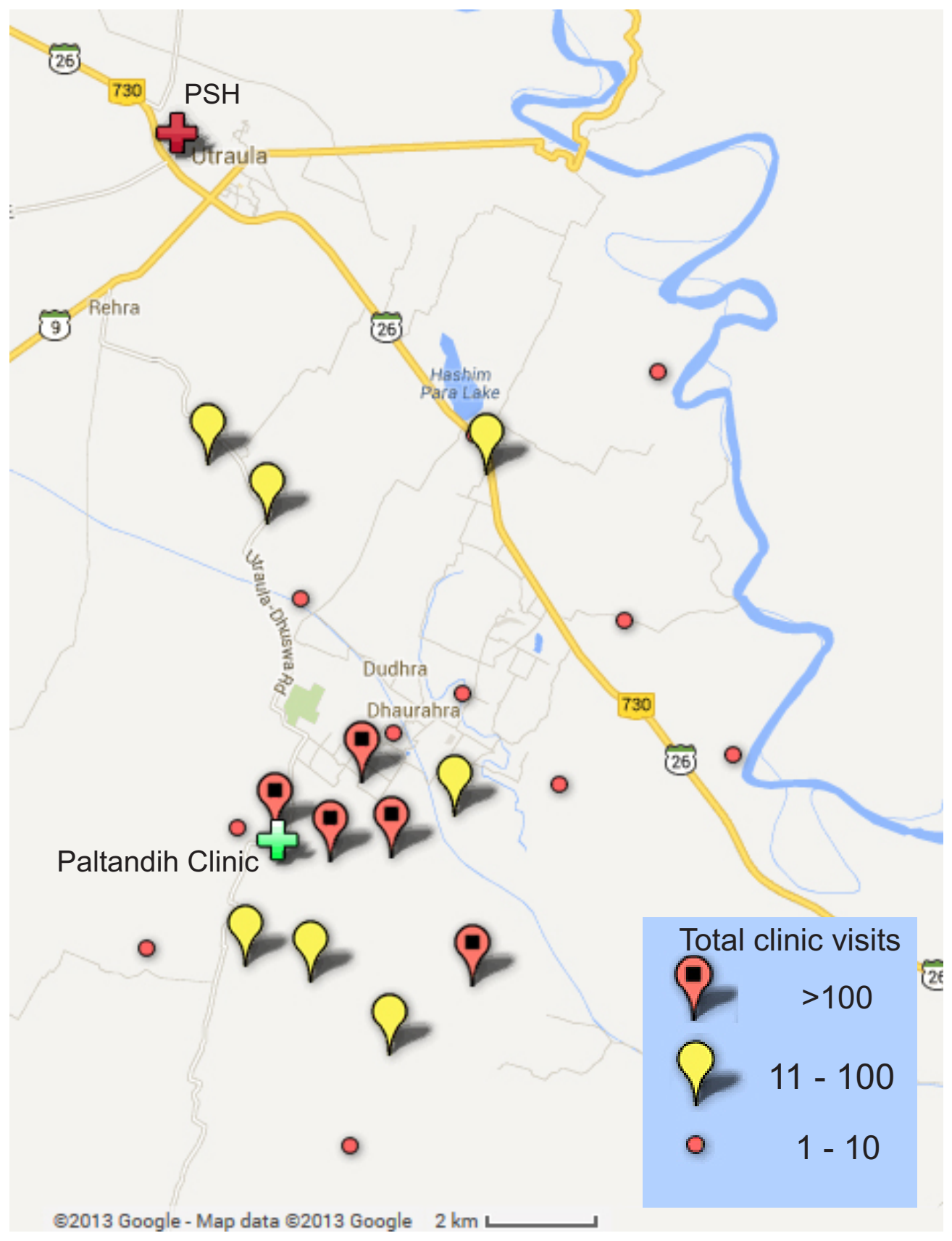

Figure 1: Total usage of Paltandih clinic from villages in Gaindas Bujurg Block, Uttar Pradesh 


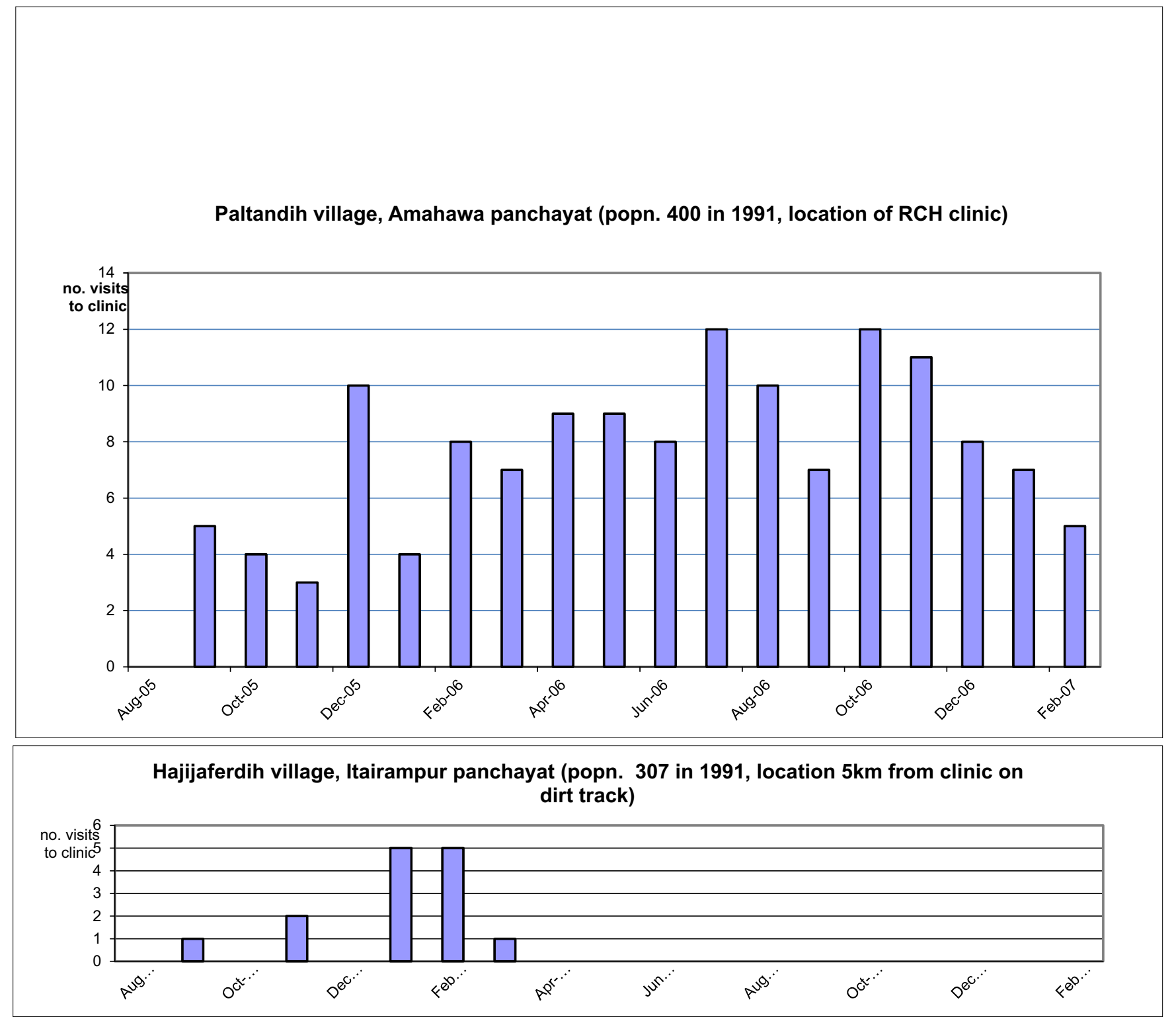

Figure 2: Examples of (a) consistent and (b) intermittent usage of clinic from villages 


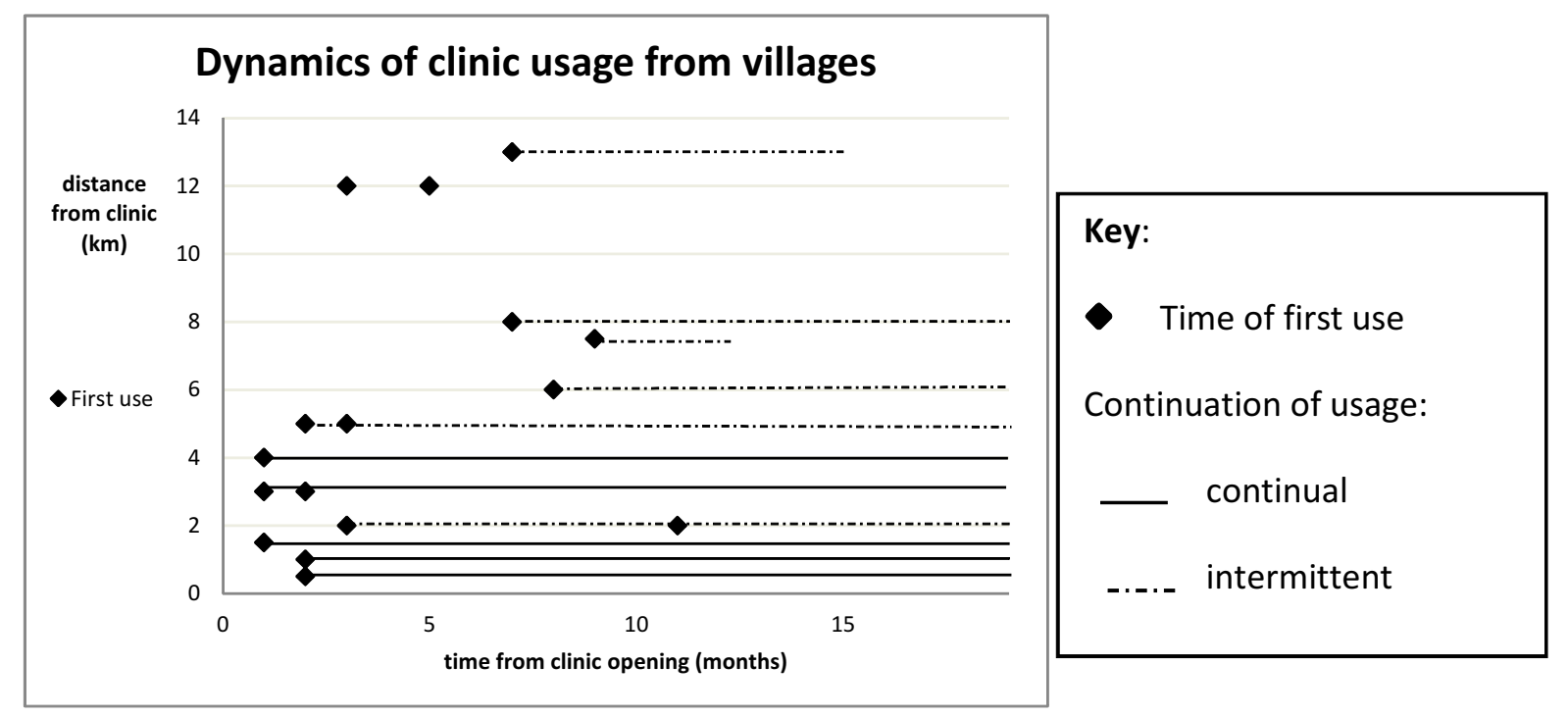

Figure 3: Dynamics of village usage

'intermittent' usage that starts and stops, either permanently or temporarily. See Figure 2 for examples of such usage.

Cumulative data for the first nineteen months of operation of the clinic are informative about the distances that people are travelling to access the clinic. Figure 4 shows the percentage of usage within given distances of the clinic. It can be seen that approximately $90 \%$ of the locatable uptake of clinic services comes from within $6 \mathrm{~km}$ of the clinic. This figure includes data only from known locations and known populations at those locations: it was noticed that non-locatable usage increased in time, perhaps as news of the clinic spread further afield.

\begin{tabular}{l|l|l|l}
\hline Distance from clinic & Popn. & first use & Nature of usage \\
\hline $0-2 \mathrm{~km}$ & $400-5000$ & after first month & consistent \\
$1.5-4 \mathrm{~km}$ & various $>400$ & from first month & consistent \\
$2-3 \mathrm{~km}$ & $<400$ & various & intermittent \\
$>4 \mathrm{~km}$ & various & various & intermittent \\
\hline
\end{tabular}

Table 1: Patterns of village usage 


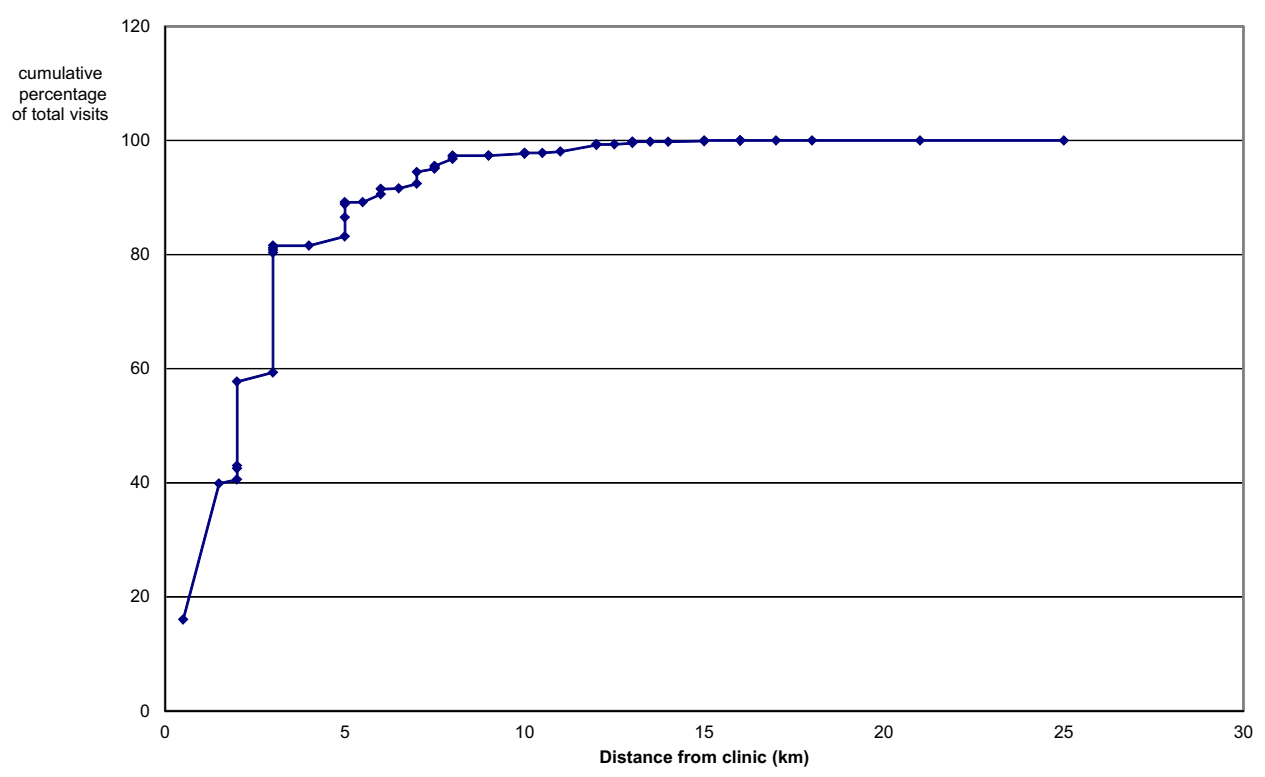

Figure 4: Cumulative percentage of clinic visits by distance

\section{$5 \quad$ Model for usage of clinic services}

We model the dynamic growth of usage of a rural healthcare facility in a geographical region. It is assumed that knowledge of the low-cost services on offer spread by word of mouth between small communities, and that there is no effective competition.

The rate of arrival of customers is assumed to depend on distance from the clinic and on whether trust in the reputation provider has built up in any particular village through spread of word-of-mouth contacts and other development work locally. The problem can thus be decomposed into spatial and spatio-temporal subproblems, the spatial being the potential for use of the service given travel distance and the spatio-temporal being the inclination for use due to sufficient trust in the provider in a village at a particular point in time.

\subsection{Assumptions regarding growth of knowledge and trust}

A number of assumptions are made about the way that word-of-mouth information and reputation or trust spreads dynamically across a rural region where travel is generally on foot. It is assumed that within a certain distance, villagers will have full knowledge of a clinic and its services, and will have no reason not to use the facility. Beyond that distance it is assumed that news will pass from one village where use is made of the facility to others within a certain neighbourhood. However, only a fraction of these more remote villages are expected to choose to take up use of the facilities. A random factor is therefore applied in our modelling for take-up of use of the facility (Friedkin, 1986). It is also assumed that the impact of one village taking up usage of the facility will affect neighbouring villages for only a limited period of time. Without this assumption, the clinic usage would spread to every village in the region, in the long term, which has not occurred.

The providers of the health facility may undertake work in more remote villages to increase awareness of the facility. It is assumed that such awareness will reduce with time unless renewed or usage is taken 


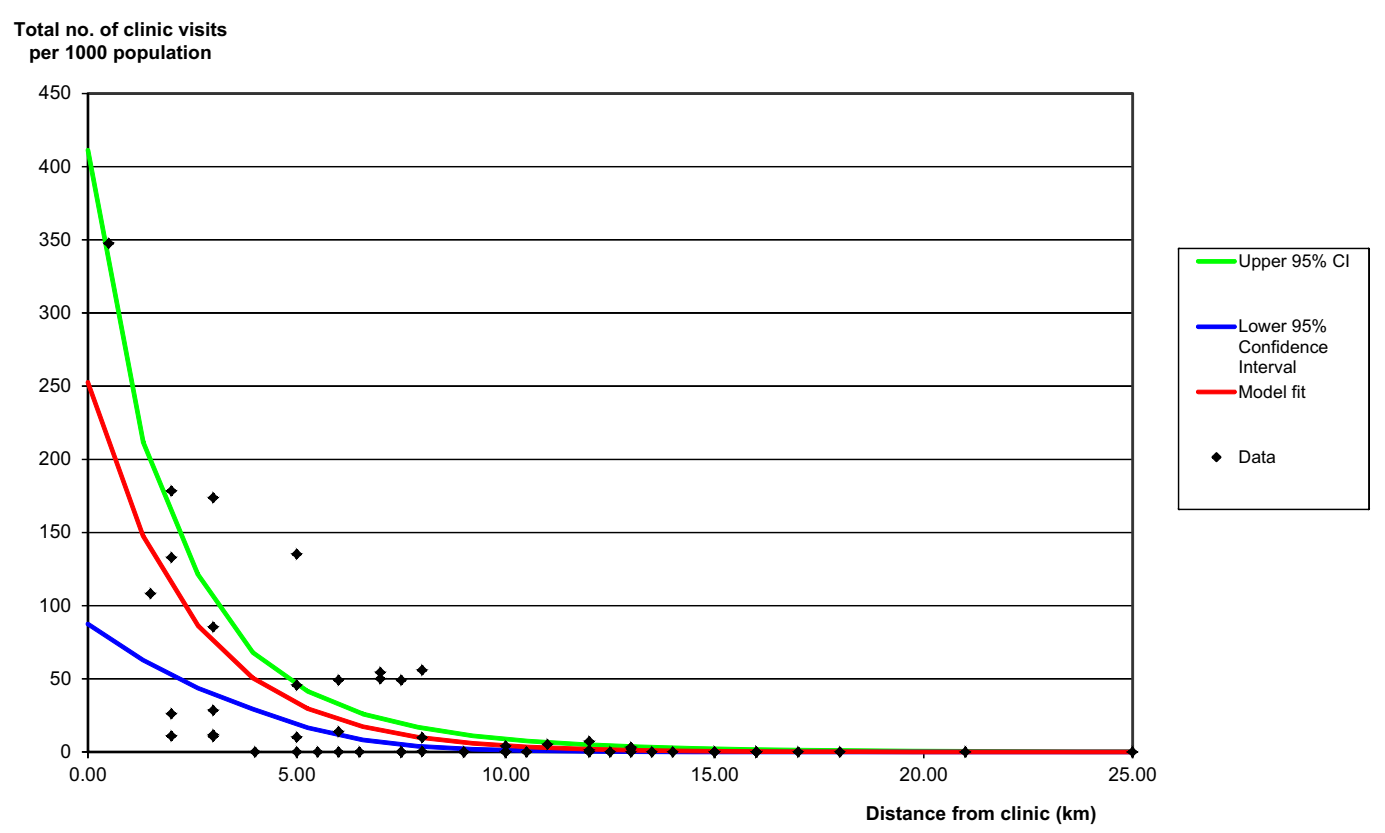

Figure 5: Total usage per village by distance from clinic, with bootstrap plots of usage confidence intervals up.

It is assumed that once usage reaches a certain level, or 'tipping point' (Gladwell, 2000) in a particular village, then local residents have accepted the benefits of utilising the facility and will continue to do so. With lower or occasional usage, however, it is assumed that this may cease randomly due to unknown factors that cannot be modelled. The assumptions are made from observations of village usage as shown in Figure 3 and of data from villages with few instances of usage.

To summarise, we assume that trust in a clinic exists or may occur in a village if any of the following "trust conditions" apply:

1. The village is close to the clinic;

2. There has been usage of the clinic from the village during the last three time periods;

3. There has been first usage from a neighbouring village during the last three time periods;

4. There has been awareness raised in the village through recent development work.

\subsection{Summary of modelling}

We summarise in this section the mathematical modelling used to predict clinic usage. Full details of the calculations of dynamic build-up of trust are given in Section 5.3.

An exponential drop-off of potential village usage is suggested by the data: see Figure 5 which shows total usage of the clinic in the nineteen-month observation period. Such a relationship between distance and usage is assumed in our modelling. We therefore model the potential rate of usage per head of population, $\lambda_{i}$, from village $i$, $i \in I$, with the logarithmic form of an exponential relationship, as follows:

$$
\log \lambda_{i}=\alpha d_{i}+\beta, \quad i \in I,
$$


where $\alpha$ and $\beta$ are model parameters to be estimated (see Section 6.1), and $d_{i}$ is the distance of village $i$ from the Paltandih clinic. As travel between villages in rural regions of developing countries is generally on foot, Euclidean measurements are assumed for distances between villages.

A Poisson distribution is used to model the numbers of clinic customers arriving from villages. The number of clinic customers arriving from village $i, i \in I$, during in month $t, t=0, \ldots, T, y_{i t}$, is given by:

$$
y_{i t} \sim \operatorname{Poisson}\left(x_{i t} p_{i} \lambda_{i}\right), \quad i \in I, t=0, \ldots, T \text {. }
$$

where the trust factor, $x_{i t}$, is calculated according to the four "trust conditions" (see Section 5.1); $p_{i}$ is the population of village $i$ and $\lambda_{i}$ is given by equation (1). Details of the calculation of $x_{i t}$ follow.

\subsection{Dynamic modelling of trust factor}

The dynamic of spread of usage of the clinic is modelled using trust factor, $x_{i t}, 0 \leq x_{i t} \leq 1$, representing the trust in the clinic in village $i$ at time $t$. If any of the four 'trust conditions' apply (see Section 5.1), $x_{i t}$ becomes positive. In the following sections we define a number of factors that describe the spread of trust from village to village.

\subsubsection{Geographical data}

The following data are input for each village, using population and geographical data:

$d_{i}=$ distance between village $i$ and the clinic, $\quad i \in I$.

$d_{i j}=$ distance between villages $i$ and $j, \quad i, j \in I$.

$p_{i}=$ population at village $i, i \in I$.

The following are estimated using local knowledge:

$D_{v c}=$ distance very close to facility, within which those living have full knowledge about the facility

but are initially reluctant to use its services.

$D_{c}=$ distance within which those living have full knowledge about the facility, its availability and services offered.

$D_{n}=$ maximum distance between villages for spread of news about clinic.

\subsubsection{Dynamic spread of clinic usage: the trust factor}

The dynamic calculations make use of the following to predict usage of a clinic:

(a) Proximity factor, $b_{i}=\left\{\begin{array}{ll}0 & \text { if } d_{i} \leq D_{v c}, \\ 1 & \text { otherwise, }\end{array} \quad i \in I\right.$. 
$b_{i}$ gives the immediate neighbourhood of the clinic, where people may show initial reluctance to use the services. (N.B. this effect may not be observed in other regions and cultures.)

(b) Closeness factor, $c_{i}=\left\{\begin{array}{ll}1 & \text { if } d_{i} \leq D_{c}, \\ 0 & \text { otherwise, }\end{array} \quad i \in I\right.$.

$c_{i}$ defines the region close to the clinic, where people have full knowledge of the services offered.

(c) Usage factor, $u_{i t}=\left\{\begin{array}{ll}1 & \text { if } y_{i, t-1}, y_{i, t-2} \text { or } y_{i, t-3}>0, \\ 0 & \text { otherwise, }\end{array} \quad i \in I, t=0, \ldots, T\right.$.

$u_{i t}$ indicates whether the facility has been used by people from village $i$ during any of the previous three periods.

(d) First use factor, $f_{i t}= \begin{cases}1 & \text { if first use from village } i \text { occurred at time } t \\ 0 & \text { otherwise }\end{cases}$

$$
i \in I, t=0, \ldots, T \text {. }
$$

(e) Neighbourhood first use factor,

$n_{i t}=\left\{\begin{array}{l}1 \quad \text { if some } f_{j k}>0, \text { where } d_{i j} \leq D_{n} \\ \quad \text { and } 1 \leq t-k \leq 3, \\ 0 \quad \text { otherwise }\end{array} \quad i, j \in I, t, k=0, \ldots, T\right.$.

$n_{i t}$ indicates whether the facility has been first used in neighbouring villages during during any of the previous three periods.

(f) Awareness factor, $a_{i t}, 0 \leq a_{i t} \leq 1$,

which gives for time $t, t=0, \ldots, T$, the proportion of people at village $i, i \in I$, likely to be aware of the facility and its services through development work. It is assumed that awareness will decay over time if not refreshed. A decay factor, $\gamma, 0 \leq \gamma \leq 1$, is an estimated model parameter:

$$
a_{i t}=\gamma a_{i, t-1}, \quad i \in I, t=0, \ldots, T \text {. }
$$

It is assumed that uptake of clinic services does not always necessarily occur, for reasons that are too complex to model. Villagers in the close vicinity of the clinic may not immediately take up use of the services. The usage by one village may not influence neighbouring villages. Development work may not persuade villagers that the services provided are of benefit. Likewise, usage from far-off villages that have made only limited use of the facility may also cease. Uncertainty in uptake of a facility is therefore modelled through random factors $\Delta_{i t}^{1}, \Delta_{i t}^{2}$ and $\Delta_{i t}^{3}$.

$$
\Delta_{i t}^{n} \sim \operatorname{Bernoulli}(\delta), i \in I, n=1,2,3, t=0, \ldots, T .
$$

where $\delta$ is an estimated model parameter.

The following factors capture uncertain uptake and ceasing of usage of a clinic's services:

(a) Random factor $r_{i t}$, 


$$
r_{i t}=\left\{\begin{array}{ll}
0 & \text { if } \Delta_{i t}^{1}=0, d_{i} \geq D_{c} \text { and } \lambda_{i}<U \\
1 & \text { otherwise, }
\end{array} \quad i \in I, t=0, \ldots, T .\right.
$$

Through $r_{i t}$, usage may cease from villages at distance greater than $D_{c}$ with low potential rate of use, $\lambda_{i}<U$.

(b) Random factor $s_{i t}$,

$$
s_{i t}=\left\{\begin{array}{ll}
0 & \text { if } \Delta_{i t}^{2}=0, d_{i} \geq D_{c} \\
1 & \text { otherwise, }
\end{array} \quad i \in I, t=0, \ldots, T .\right.
$$

Via this random factor, influence from neighbouring villages is taken up randomly.

With the above definitions and equation (3), we calculate the trust factor, $x_{i t}$, according to the four "trust conditions" (see Section 5.1):

$$
x_{i t}=\max \left\{b_{i} c_{i}, s_{i t} n_{i t}, r_{i t} u_{i t}, \Delta_{i t}^{3} b_{i} a_{i t}\right\}, \quad i \in I, t=0, \ldots, T .
$$

Finally, using equations (1) and (5) in (2), we calculate $y_{i t}$, the number of clinic customers from village $i$, arriving at time $t$.

\section{Model calibration}

Usage from each village, as calculated by equation (2), was modelled by Monte Carlo simulation, built in Microsoft Visual C++.NET@ using the Visual Studio@ development environment. A Poisson sample generator was used that was suited to the size of the means (Cheng, 1998).

To estimate parameters, the problem is decomposed into spatial and spatio-temporal subproblems. Parameters $\alpha$ and $\beta$ in equation (1) are concerned solely with distance data. For their estimation, data were used on total numbers of visits made to the clinic by distance, as illustrated in Figure 5.

Parameters $\gamma$ and $\delta$ (see Section 5.3.2) are essentially concerned with dynamic effects over the area concerned; these parameters were estimated separately using simulations of the spread of usage in time through the region. In this process, values of $\alpha$ and $\beta$ were used as already determined.

\subsection{Maximum Likelihood Estimation of parameters $\alpha$ and $\beta$ with bootstrapping}

Parameters $\alpha$ and $\beta$ were estimated using Maximum Likelihood Estimation (Fisher, 1922, 1925), whereby the log-likelihood function for the sample is maximised. Assuming a Poisson distribution, and using equation (1), the $\log$ likelihood function $L\left(y_{i}, d_{i}, \alpha, \beta\right)$ is given by:

$$
L\left(y_{i}, d_{i}, \alpha, \beta\right)=\sum_{i \in I}-e^{\alpha d_{i}+\beta}+y_{i}\left(\alpha d_{i}+\beta\right) .
$$

where $y_{i}$ is the total number of visits, per thousand population, from village $i$ at distance $d_{i}$ from the clinic.

For the maximisation, a Nelder-Mead optimisation routine (Nelder and Mead, 1965) was utilised, obtaining optimal values of $\alpha=-.41$ and $\beta=5.53$ over the nineteen-month period of observation. This corresponds to a value of

$$
\beta=5.53-\log _{e}(19)=2.59
$$




\begin{tabular}{|c|c|c|c|c|c|c|c|c|}
\hline \multirow[b]{4}{*}{$\delta$} & \multicolumn{8}{|c|}{$\begin{array}{l}\text { Sensitivity to values of } \gamma \text { and } \delta \\
\text { average monthly total number visits to clinic, } \\
\text { number of villages with usage }>0\end{array}$} \\
\hline & \multicolumn{8}{|c|}{$\gamma$} \\
\hline & \multicolumn{2}{|c|}{0.3} & \multicolumn{2}{|c|}{0.4} & \multicolumn{2}{|c|}{0.5} & \multicolumn{2}{|c|}{0.6} \\
\hline & $\begin{array}{c}\max . \\
\text { av. }\end{array}$ & $\begin{array}{c}\text { no. } \\
\text { villages }\end{array}$ & $\begin{array}{c}\max . \\
\text { av. }\end{array}$ & $\begin{array}{c}\text { no. } \\
\text { villages }\end{array}$ & $\begin{array}{c}\max . \\
\text { av. }\end{array}$ & $\begin{array}{c}\text { no. } \\
\text { villages }\end{array}$ & $\begin{array}{c}\max . \\
\text { av. }\end{array}$ & $\begin{array}{c}\text { no. } \\
\text { villages }\end{array}$ \\
\hline 0.4 & 94.5 & 23 & 95.7 & 23 & 95.9 & 23 & 96.1 & 23 \\
\hline 0.5 & 89.9 & 23 & 91.7 & 23 & 92.0 & 23 & 93.3 & 23 \\
\hline 0.6 & 86.6 & 22 & 88.9 & 22 & 90.0 & 22 & 91.4 & 22 \\
\hline
\end{tabular}

Table 2: Sensitivity to $\gamma$ and $\delta$

for each one-month period used in our modelling. Five hundred instances of the variables were simulated using bootstrapping (Simon, 1969; Efron, 1982; Davison and Hinkley, 1997), giving confidence intervals as shown in Figure 5 .

\subsection{Estimation of $\gamma$ and $\delta$ by simulation}

Parameter $\gamma$ (equation 3) captures the on-going effectiveness of some event causing awareness of the clinic. Increase of $\gamma$ causes more villages to take up use of the clinic. Parameter $\delta$ (equation 4) sets the level of random usage of the clinic. Increase of $\delta$ causes less villages to begin to use the clinic, and more villages to cease use of the clinic.

One hundred simulations were carried out for each of a grid of values of $\gamma$ and $\delta$, to determine optimal values for these parameters, with $\alpha=-.41$ and $\beta=2.59$ as obtained above. The model was calibrated for both the maximum average monthly total number of clinic visits and the number of villages using the clinic. Table 2 gives sensitivity of these indicators across a range of values of $\gamma$ and $\delta$. Values of $\gamma=0.3$ and $\delta=0.5$ were selected for the model, as these give a range of monthly total number visits to clinic corresponding well to the actual, with appropriate number of villages using the clinic.

\subsection{Estimation of distance parameters $D_{v c}, D_{c}$ and $D_{n}$ and usage rate $U$}

Use of these parameters is described in detail in Section 5.3.2. Distance parameter $D_{c}$ defines the distance defined by immediate use of the clinic through living close enough to have knowledge of the services offered. Distance $D_{v c}$ gives the region so close to the clinic that residents are reticent to use the facility. Parameters $D_{v c}, D_{c}$ were set by visual inspection of the data, taking values of $D_{v c}=1 \mathrm{~km}$ and $D_{c}=4 \mathrm{~km}$. Parameter $D_{n}$ represents the distance between neighbouring villages across which news and experience of the clinic is likely to travel by word of mouth. This was estimated to be $2 \mathrm{~km}$, as daily travel is limited.

Usage rate $U$ gives the threshold rate below which usage may be intermittent from far-off villages: from inspection of the data, a monthly usage rate of 5 visits per 1000 population was chosen. 


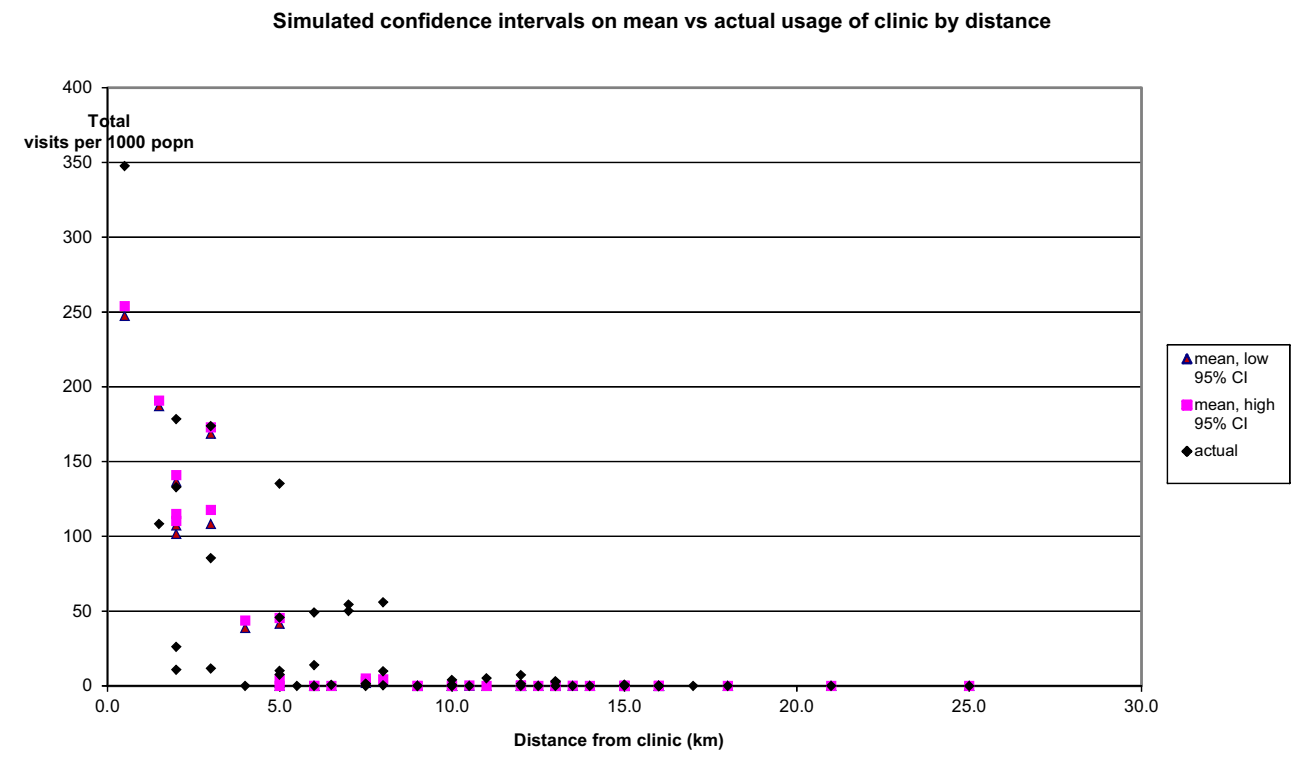

Figure 6: Comparison of simulated mean usage with actual total usage by distance from clinic

\section{Results of simulation}

The following results were obtained from 100 simulation runs, with model parameter settings of $\alpha=$ $-0.41, \beta=2.59, \gamma=0.3, \delta=0.5$, distances $D_{v c}=1 \mathrm{~km}, D_{c}=4 \mathrm{~km}, D_{n}=2 \mathrm{~km}$. These values of the parameters had been found optimal to describe the actual data, with regards usage from the closest villages, the proportion of villages starting to use the facility and drop-off of usage further away.

Figure 6 shows the $95 \%$ confidence intervals on simulated mean values for total usage from villages, per thousand population, by distance from the clinic. A comparison can be seen with actual usage figures from villages. There is underestimation of usage from the clinic location itself. There is slight overestimation of usage from close villages (up to $5 \mathrm{~km}$ ) and underestimation of usage from middle-distance villages (from 5 to $12 \mathrm{~km})$.

Figure 7 shows actual total usage by month compared to simulated $95 \%$ confidence intervals of the mean usage. Simulated use of the clinic in the early months is higher than actual usage: we have not modelled a warm-up period of use of the clinic. The last three months were overestimated because of the unanticipated closure of the clinic on a number of days. There is apparent overestimation of the mean usage: in fact the modal value of the actual monthly total usage is lower than the mean.

It should be noted that we have reported the mean simulated usage, providing confidence intervals on this measure, and compared this with the actual values of usage. This shows the build-up in time of the total usage of the clinic, and whether it can reach sustainability. For reasons of space, we cannot include here the graphs of the simulated usage from all villages. It can be observed that with the $\alpha$ and $\beta$ parameter settings used, there is under- and over- estimation in the regions right by and close to the clinic, with some overall overestimation. Adjustment of the $\gamma$ and $\delta$ parameters is associated with the uptake of services by far-off villages: this adjustment can give lower total usage, but at the cost of losing usage altogether from more remote villages. 


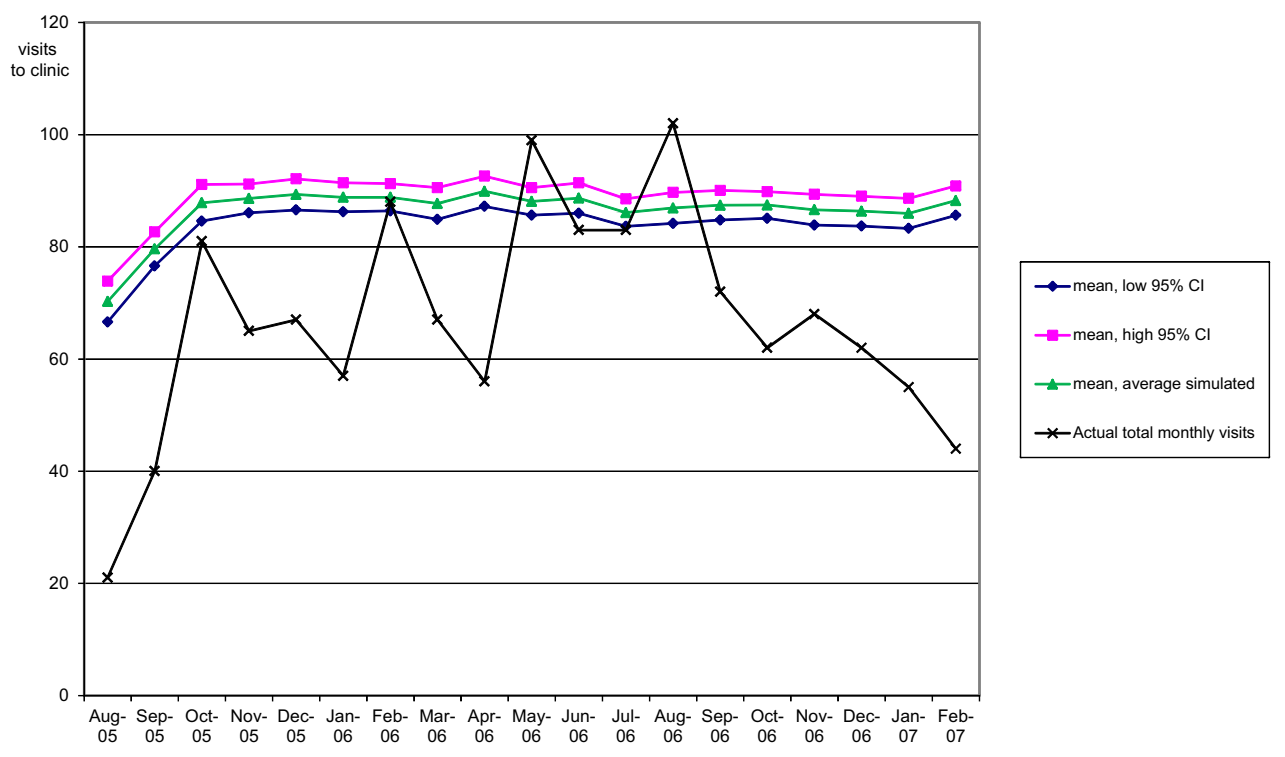

Figure 7: Total usage for clinic by month: comparison of simulated mean with actual

\section{Discussion}

The methodology demonstrated in the preliminary analysis and for the simulation, taken together, can be used practically to establish likely catchment areas and rate of spread of usage for a similar clinic. It should be noted that our model is not designed to predict what usage will arise from any particular village, but rather to indicate overall patterns. It is important to note the conditions in which more generic application of this modelling is possible. One condition is the absence of other competing health facilities to choose from: this can be experienced in many remote areas of developing countries. Similarly, we suggest that the spread of knowledge by word of mouth only across a geographical reason can occur in many such regions. Once the parameters have been determined using one data set, the model would be suitable to apply, for example, to another geographical area that had similar cultural and economic characteristics. So, for example, modelling could be applied to a second block in the same district where PSH was planning to start a second community clinic, in order to estimate future usage.

Our modelling echoes the trustee characteristics and trusting types of McKnight and Chervany (2001). The trust modelling (Section 5.3) has underlying assumptions that the healthcare provider is competent, benevolent and predictable. It is assumed that trusting beliefs in the healthcare provider or intentions to obtain service can arise from positive experiences both in the close neighbourhood of the clinic, in villages further afield and through development activities in villages. However, we have limited our modelling to the positive side: there was no evidence of negative incidents causing distrusting beliefs or actions. Moreover, as Lewis and Weigert (1985) suggest, we demonstrate build-up of trust village by village, i.e. as a group experience.

We acknowledge that our suggestion that usage of a health service occurs as a result of trust in the service is open to debate. Ozawa and Sripad (2013), in their systematic review of measures of trust in health systems, assert that trust has a role in usage of health facilities, but find a majority of studies only in the context of the US health system. Similarly, while Brennan et al (2013) recognise the importance of trust as a possible indicator of how patients evaluate quality of a healthcare service, it is again found 
that most research into this area has been carried out in the USA. As indicated in Section 1, Russell (2005) and Rao et al (2013) provide examples of research into trust in healthcare providers in developing countries, but this remains an area where more evidence-based research would be informative.

We consider also limitations of the study in terms of validation, considering the study components of data collection, assumptions and modelling. A number of inaccuracies may have been present in the input data for our case study, due to uncertainty of the locations and populations of the home villages of clinic customers. The small numbers of clinic visits occurring for our case study, typically 60-100 visits per month from the entire region, also makes prediction difficult from such a complex region. Furthermore, the study considers populations only within the local block, ignoring other potential users of the facility. Such inaccuracies could have affected determination of parameter values. We feel, nevertheless, that a sufficiently accurate picture was presented from the data that was available, to make modelling valid.

More time spent in the region would have enabled further research into some of the fundamental assumptions of the modelling, such as the modes of travel in the area and distances involved in the spreading of ideas between villages. Similarly, validation of the model using a second dataset would have been highly desirable, but was impossible for reasons of distance and logistical problems.

\section{Conclusion}

We have demonstrated the modelling of the growth of trust and usage in a community clinic as news travels throughout a geographical area. Our study contributes to the literature with a practical application of trust modelling, an area of study which has hitherto been generally of a theoretical nature.

On the basis of this case study, we make some observations about the planning of sustainable community health clinics in developing countries. In analysing data from this rural community clinic, the picture emerges of highest usage occurring within a small radius of travel, with more distant settlements contributing to usage at a lower but not insubstantial level. This pattern can be utilised in the planning process. Development work, particularly with on-going healthcare education, is clearly advantageous to raise awareness of the benefits of a community clinic and to build trust. To ensure sustainability of such a clinic, this work should be targeted at population centres at a suitable distance likely to raise usage, and at those from which expected usage has been lacking.

Other considerations for sustainability arise with a facility that is part of a hospital service. The existence of the $\mathrm{RCH}$ clinic depends on the commitment of the hospital to the clinic and to its nurses, who work in conditions very different from those in in the hospital. Moreover, the referral system to the hospital makes it important that referred patients are made to feel welcome by staff in the larger facility, again so that trust can be maintained.

Our particular interest in this research has been in analysing and modelling clinic usage, as usage is one of the major factors determining sustainability of such a facility. Such considerations apply to any community health facility that is funded wholly or partially by user payments, or even one that is completely externally funded but with a target capacity. To the date of the case study, usage for the Paltandih clinic studied had not reached the point of covering all costs. However, the strong commitment of the hospital was likely to maintain the clinic's presence in the area without recourse to further external funding. The hospital management could clearly see the value to the community and to the hospital of 
maintaining this comparatively low cost but effective service, in an area not otherwise resourced adequately by the distant presence of the hospital or by government provision. Sustainability was therefore likely to be achieved.

Taking the whole dynamic picture into account, this type of modelling is able to give a useful reproduction of likely use of clinic facilities in a region where information about services and trust is spread by word of mouth. Our modelling methodology, with a dynamic trust factor applied to spatial usage, is able to inform strategic capacity planning for sustainability of a similar type of facility, in similar rural areas of developing countries. An essential characteristic of an area affecting spread of influence or trust is the density of villages in a region, but also cultural factors affect the transmission of influences. Having calibrated the model in one area, it would be suitable to apply in a similar geographical and cultural region.

The area of research into prediction of demand for healthcare facilities is likely to continue to fruitful, as planning of expensive and much needed facilities should be based on well considered predictions. One area that can be further explored is that of agent-based simulation of the build-up of trust in a facility. The potential for use of agent-based simulation is becoming increasingly of interest where models can be validated by data rather than being purely descriptive.

\section{Acknowledgements}

We thank the anonymous referees whose suggestions have considerably improved this paper.

This research was funded by the UK Engineering and Physical Sciences Research Council: DTA Grant EP/P500478/1 and Science and Innovation grant EP/F033982/1.

Our grateful thanks go to Dr Ann Thyle of Emmanuel Hospital Association, whose vision for a sustainable clinic inspired this study. The busy staff of Prem Sewa Hospital and the Paltandih Clinic gave much assistance. Without the kind support of Dr Ronghaklien Joute, Medical Superintendent and Senior Administrative Officer of Prem Sewa, our visit and data collection could not have taken place. Sadly, Dr Joute died not long after our visit. We are grateful for the advice of Prof Russell Cheng on parameter estimation and bootstrapping. Jon Smith of Selective Analytics Ltd gave much-needed help with mapping and graphics.

\section{References}

Andersen RM (1995). Revisiting the behavioral model and access to medical care: does it matter? Journal of Health and Social Behavior 36: 1-10.

Belen S, Kropat E and Weber G-W (2011). On the classical Maki-Thompson rumour model in continuous time. Central European Journal of Operations Research 19: 1-17.

Boender GJ, Meester R, Gies E and De Jong MCM (2007). The local threshold for geographical spread of infectious diseases between farms. Preventive Veterinary Medicine 82: 90-101.

Brandeau M, Chiu S, Khumar S and Grossman T (1995). Location with market externalities. In: Drezner Z (ed). Facility Location: A Survey of Applications and Methods. Springer-Verlag: Berlin, pp 121-150. 
Brennan N, Barnes R, Calnan M, Corrigan O, Dieppe P and Entwistle V (2013). Trust in the health-care provider-patient relationship: a systematic mapping review of the evidence base. International Journal for Quality in Health Care 25: 682-688.

Census of India (1991). Census of India, 1991. Office of the Registrar General and Census Commissioner, Ministry of Home Affairs: Delhi.

Census of India (2001). Census of India, 2001. Office of the Registrar General and Census Commissioner, Ministry of Home Affairs: Delhi.

Cheng RCH (1998). Random variate generation. In: Banks J (ed). Handbook of Simulation: Principles, Methodology, Advances, Applications, and Practice. Wiley: New York, pp 139-172.

Daley DJ and Kendall DG (1965). Stochastic rumours. Journal of the Institute of Mathematics and its Applications 1: 42-55.

Davison AC and Hinkley DV (1997). Bootstrap Methods and their Application. Cambridge University Press: Cambridge.

DeGroot MH (1974). Reaching a consensus. Journal of the American Statistical Association 69: 118-121.

Doreian P (1981). Estimating linear models with spatially distributed data. In: Leinhardt S (ed). Sociological Methodology. Jossey-Bass: San Francisco, pp 359-388.

Efron B (1982). The Jackknife, the Bootstrap, and other Resampling Plans, SIAM Monograph \#38. Society for Industrial and Applied Mathematics: Philadelphia.

Fisher RA (1922). On the mathematical foundations of theoretical statistics. Philososphical Transactions of the Royal Society of London, Series A 222: 309-368.

Fisher RA (1925). Theory of statistical information. Proceedings of the Cambridge Philosophical Society 122: $700-725$.

Fotheringham AS (1983). A new set of spatial-interaction models; the theory of competing destinations. Environment and Planning A 15: 15-36.

French JRPJ (1956). A formal theory of social power. The Psychological Review 63: 181-194.

Friedkin NE (1986). A formal theory of social power. Journal of Mathematical Sociology 12: 103-126.

Friedkin NE and Johnsen EC (1990). Social influence and opinions. Journal of Mathematical Sociology 15: $193-205$.

Gans G, Jarke M, Kethers S and Lakemeyer G (2003). Continuous requirements management for organisation networks: a (dis)trust-based approach. Requirements Engineering 8: 4-22.

Gladwell M (2000). The Tipping Point. Little, Brown and Company: London.

Gould RV (1991). Multiple networks and mobilisation in the Paris Commune, 1871. American Sociological Review 56: 716-729. 
Grossman TA and Brandeau ML (2002). Optimal pricing for service facilities with self-optimising customers. European Journal of Operational Research 141: 39-57.

Heinhold M (1978). An operational research approach to allocation of clients to a certain class of service institutions. Journal of the Operational Research Society 29: 273-276.

Hodgson MJ (1988). An hierarchical location-allocation model for primary health care delivery in a developing area. Social Science and Medicine 26: 153-161.

Hosmer LT (1995). Trust: The Connecting Link between Organizational Theory and Philosophical Ethics. The Academy of Management Review 20 (2): 379-403.

Huff DL (1964). Defining and estimating a trade area. Journal of Marketing 28: 34-38.

Kethers S, Gans G, Schmitz D and Sier D (2005). Modelling trust relationships in a healthcare network: Experiences with the TCD framework. In: Bartmann D, Rajola F, Kallinikos J, Avison D, Winter R, Ein-Doe P, Becker J, Bodendorf F and Weinhardt C (eds). Proceedings of the 13th European Conference on Information Systems (ECIS), Information Systems in a Rapidly Changing Economy, ECIS 2005, May 26-28, 2005. Institute of Management of Information Systems: Regensburg, pp 1321-1328.

Land KC, Deane G and Blau JR (1991). Religious pluralism and church membership: a spatial diffusion model. American Sociological Review 56: 237-249.

Lasker JN (1981). Choosing among therapies: illness behaviour in the Ivory Coast. Social Science and Medicine 15A: 157-168.

Lewis JD and Weigert A (1985). Trust as a Social Reality. Social Forces 63(4): 967-985.

Maki DP and Thompson M (1973). Mathematical Models and Applications. Prentice-Hall: Englewood Cliffs.

Marianov V, Serra D (2001). Hierarchical location-allocation models for congested systems. European Journal of Operational Research 135: 195-208.

Marsden PV and Friedkin NE (1994). Network studies of social influence. In: Wasserman S, Faust K (eds). Social Network Analysis. Cambridge University Press: Cambridge, pp 3-25.

Marsh S and Dibben MR (2005). Trust, untrust, mistrust and distrust - an exploration of the dark(er) side. In: Herrmann P, Issarny V, Shiu S (eds). Trust Management: Proceedings of Third International Conference, ITrust 2005, Paris, France, May 2005. Springer: Berlin, pp 17-33.

McKnight DH and Chervany NL (2001). Trust and distrust definitions: one bite at a time. In: Falcone R, Singh M, Tan Y-H (eds). Trust in Cyber-societies: Integrating the Human and Artificial Perspectives. Springer: Berlin, pp 27-54.

Müller I, Smith T, Mellor S, Rare L and Genton B (1998). The effect of distance from home on attendance at a small rural health centre in Papua New Guinea. International Journal of Epidemiology 27: 878-884. 
Nelder JA and Mead R (1965). A simplex method for function minimization. The Computer Journal 7: $308-313$.

Oliveira MD (2004). Modelling demand and supply influences on utilization: a flow demand model to predict hospital utilization at the small area level. Appled Economics 36: 2237-2251.

Ozawa S and Sripad P (2013). How do you measure trust in the health system? A systematic review of the literature. Social Science \& Medicine 36(SI): 10-14.

PSH (2007). Prem Sewa Hospital Society, Utraula, Uttar Pradesh, India, Annual Report 2006-2007. Prem Sewa Hospital Society: Utraula.

Rao KD, Stierman E, Bhatnagar A, Gupta G and Gaffar A (2013). As good as physicians: patient perceptions of physicians and non-physician clinicians in rural primary health centers in India. Global Health: Science and Practice 1(3): 397-406.

Ramchurn SD, Huynh D and Jennings NR (2004). Trust in multi-agent systems. The Knowledge Engineering Review 19: 1-25.

Roberts MG, Baker M, Jennings LC, Sertsou G and Wilson N (2007). A model for the spread and control of pandemic influenza in an isolated geographical region. Journal of the Royal Society Interface 4: $325-330$.

Russell S (2005). Treatment-seeking behaviour in urban Sri Lanka: Trusting the state, trusting private providers. Social Science and Medicine 61: 1396-1407.

Shapiro SP (1987). The Social Control of Impersonal Trust. American Journal of Sociology 93(3): 623-658.

Simon KJ (1969). Basic Research Methods in Social Science. Random House: New York.

Smith HK, Harper PR, Potts CN and Thyle A (2009). Planning sustainable community health schemes in rural areas of developing countries. European Journal of Operational Research 193: 768-777.

Schultz GP (1970). The logic of health care facility planning. Socio-Economic Planning Sciences 4: 383393.

Smallman-Raynor M and Cliff AD (2004). The geographical spread of cholera in the Crimean War: epidemic transmission in the camp systems of the British Army of the East, 1854-55. Journal of Historical Geography 30: 32-69.

Stummer C, Doerner K, Focke A and Heidenberger K (2004). Determining location and size of medical departments in a hospital network: a multiobjective decision support approach. Health Care Management Science 7: 63-71.

Xu X-J, Wang W-X, Zhou T, Chen G (2006). Geographical effects on epidemic spreading in scale-free networks. International Journal of Modern Physics C 17, 1815. DOI: 10.1142/S0129183106010194.

Yu ESK (1995). Modeling Strategic Relationships for Process Reengineering. PhD thesis, University of Toronto, Canada. 